\title{
Reported reasons for missing data and the interplay with trial setting
}

\author{
Anna Kearney ${ }^{1 *}$, Naomi Bacon ${ }^{1}$, Anna Rosala-Hallas ${ }^{1}$, Anne Daykin², Ali Heawood ${ }^{2}$, Athene Lane², Jane Blazeby², \\ Mike Clarke ${ }^{3}$, Paula Williamson ${ }^{1}$, Carrol Gamble ${ }^{1}$ \\ From 3rd International Clinical Trials Methodology Conference \\ Glasgow, UK. 16-17 November 2015
}

Missing data in clinical trials is common. It can reduce trial efficiency and bias the estimate of treatment effect.

Much emphasis is placed on addressing missing data in trial design. However, strategies need to be informed by the reasons for attrition which are likely to vary according to trial context. In order to develop effective interventions to minimise missing data, it is important to not only understand the causes but also their interplay with the trial setting.

We present the reported reasons for missing data within a cohort of 168 randomised trials published in four major journals in 2013 and 36 Health Technology Assessment programme monographs published 2009-2014.

We discuss the frequency of missing data and differential attrition resulting from causes such as withdrawals due to treatment tolerance or efficacy, inability to measure the primary outcome due to intervening outcomes such as death or illness, laboratory or technological problems, missed measurements by clinical staff and failure of patients to attend visits or return measurements. The frequency of Investigator led post randomisation exclusions will also be reviewed, looking at data excluded for reasons such as protocol violations, post randomisation ineligibility, patients not receiving the intervention or poor treatment adherence.

Levels of missing data and associations with trial setting such as clinical speciality, method and location of primary outcome measurement, nature of the intervention and control, mean age of recruited patients, number of trial centres and countries will be presented.

\section{Authors' details}

'University of Liverpool, Liverpool, UK. ²University of Bristol, Bristol, UK.

${ }^{3}$ Queen's University, Belfast, UK.

'University of Liverpool, Liverpool, UK

Full list of author information is available at the end of the article
Published: 16 November 2015

\author{
doi:10.1186/1745-6215-16-S2-P101 \\ Cite this article as: Kearney et al.: Reported reasons for missing data
} and the interplay with trial setting. Trials 2015 16(Suppl 2):P101.

Submit your next manuscript to BioMed Central and take full advantage of:

- Convenient online submission

- Thorough peer review

- No space constraints or color figure charges

- Immediate publication on acceptance

- Inclusion in PubMed, CAS, Scopus and Google Scholar

- Research which is freely available for redistribution

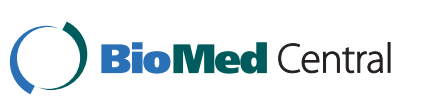

(c) 2015 Kearney et al. This is an Open Access article distributed under the terms of the Creative Commons Attribution License (http:// creativecommons.org/licenses/by/4.0), which permits unrestricted use, distribution, and reproduction in any medium, provided the original work is properly cited. The Creative Commons Public Domain Dedication waiver (http://creativecommons.org/publicdomain/ zero/1.0/) applies to the data made available in this article, unless otherwise stated. 